\title{
Modeling inflammation and oxidative stress in gastrointestinal disease development using novel organotypic culture systems
}

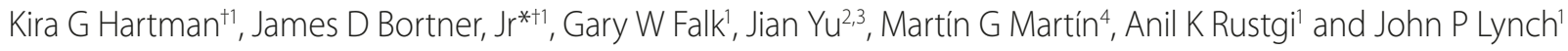

\begin{abstract}
Gastroesophageal reflux disease (GERD), Barrett's esophagus (BE), graft-versus-host disease (GVHD), and inflammatory bowel diseases such as ulcerative colitis and Crohn's disease are common human gastrointestinal diseases that share inflammation as a key driver for their development. A general outcome resulting from these chronic inflammatory conditions is increased oxidative stress. Oxidative stress is caused by the generation of reactive oxygen and nitrogen species that are part of the normal inflammatory response, but are also capable of damaging cellular DNA, protein, and organelles. Damage to DNA can include DNA strand breaks, point mutations due to DNA adducts, as well as alterations in methylation patterns leading to activation of oncogenes or inactivation of tumor suppressors. There are a number of significant long-term consequences associated with chronic oxidative stress, most notably cancer. Infiltrating immune cells and stromal components of tissue including fibroblasts contribute to dynamic changes occurring in tissue related to disease development. Immune cells can potentiate oxidative stress, and fibroblasts have the capacity to contribute to advanced growth and proliferation of the epithelium and any resultant cancers. Disease models for GERD, BE, GVHD, and ulcerative colitis based on three-dimensional human cell and tissue culture systems that recapitulate in vivo growth and differentiation in inflammatory-associated microphysiological environments would enhance our understanding of disease progression and improve our ability to test for diseaseprevention strategies. The development of physiologically relevant, human cell-based culture systems is therefore a major focus of our research. These novel models will be of enormous value, allowing us to test hypotheses and advance our understanding of these disorders, and will have a translational impact allowing us to more rapidly develop therapeutic and chemopreventive agents. In summary, this work to develop advanced human cell-based models of inflammatory conditions will greatly improve our ability to study, prevent, and treat GERD, BE, GVHD, and inflammatory bowel disease. The work will also foster the development of novel therapeutic and preventive strategies that will improve patient care for these important clinical conditions.
\end{abstract}

Keywords: inflammation, oxidative stress, DNA damage, gastrointestinal disease, gastroesophageal reflux disease, Barrett's esophagus, graft-versus-host disease, inflammatory bowel disease, human three-dimensional organotypic model systems

\section{Introduction}

Inflammation initiated by an immune response targets epithelial cells, leading to cytotoxic effects, and is a key driver of several disease conditions in the gastrointestinal (GI) tract [1]. Chronic inflammation leads to increased

\section{${ }^{+}$Contributed equally}

*Correspondence: jbor@mail.med.upenn.edu

'Division of Gastroenterolgy, Department of Medicine, Abramson Cancer Center, University of Pennsylvania, 3451 Walnut Street, Philadelphia, PA 19104, USA

Full list of author information is available at the end of the article oxidative stress and long-term consequences, most notably cancer [2]. Oxidative stress is caused, in part, by highly reactive oxygen species (ROS) and nitrogen species (for example, superoxide anions, hydrogen peroxide, nitric oxide, and peroxynitrite), which can damage proteins, lipids, DNA, and organelles, leading to altered phenotypic patterns, the induction of metaplasia, the transformation of the epithelium, and the emergence of cancer $[2,3]$.

Inflammation-associated conditions in the GI tract include gastroesophageal reflux disease (GERD), Barrett's esophagus (BE), graft-versus-host disease (GVHD), and inflammatory bowel disease (IBD; that is, ulcerative 
colitis and Crohn's disease). Induction of GERD and BE requires gastric acid and bile reflux to induce tissue injury, which results in the release of proinflammatory cytokines and subsequent recruitment of inflammatory cells [4-6], while GVHD results from donor-derived $\mathrm{T}$ lymphocytes damaging host tissue in response to MHC disparities [7], and ulcerative colitis and Crohn's disease are caused, in part, by dysregulation of mucosal immunity [8]. These diseases are important US healthcare concerns associated with significant morbidity and mortality [9-12].

\section{Knowledge gaps}

Mouse transgenic and surgical models have been the primary means of mechanistic studies for investigating inflammation-based GI diseases. While these models have been useful, they have obvious limitations because mice do not normally develop BE or ulcerative colitis [13]. Improved models based on human cells and tissues are urgently needed to understand pathogenesis as well as to explore novel therapeutic strategies. The lack of robust models has been a major impediment to these fields.

Cell culture has been used in several forms for the study of GI disease [14]. The use of human cells in tissue culture systems, such as proposed here, allows for the ability to mimic the in vivo interplay between the epithelium, immune cells, and the underlying stroma, providing a microphysiologically relevant environment [14] (Figure 1a). Immune cells activated in response to tissue injury or other mechanisms are significant producers of ROS, including hydrogen peroxide, and secrete cytokines that further amplify endogenous and exogenous ROS (Figure 1b,c). In the esophagus and intestine, esophagitis and acute IBD elicit the expression of Thelper type 1 proinflammatory cytokines such as IL-1 $\beta$, IL-8, and IFN $\gamma$, while BE and the later stages of IBD present with a predominantly T-helper type 2 humoral response, with significantly increased levels of IL-4 $[15,16]$. However, the mechanism by which this inflammatory process results in metaplasia, dysplasia, and cancer is not known.

Current models suggest ROS generated by immune cell responses induce DNA single and double-stranded breaks or modify DNA bases by forming adducts (Figure 1a). The major forms of oxidative DNA damage are nonbulky lesions such as 8-oxo-2'-deoxyguanosine and thymine glycol [17]. These modifications can lead to base mispairing and point mutations that, if not corrected prior to DNA replication, can cause mutations that activate oncogenes or inactivate tumor suppressors [18]. Furthermore, epigenetic changes in gene expression can also enhance disease progression [19]. Using artificial approaches (addition of hydrogen peroxide to cell cultures), oxidative stress was recently established to profoundly alter epigenetic patterning in vitro [17]. Using physiologically relevant conditions, however, it remains unproven whether the oxidative stress associated with inflammatory responses is the primary driver of the pathogenesis of BE, GVHD, and IBD, and the dysplasia and cancer associated with BE and IBD.

Esophageal three-dimensional (3D) organotypic culture (OTC) methods utilize epithelial cells grown on top of collagen/Matrigel matrices containing human fetal esophageal fibroblasts [20]. OTC methods provide a highly physiological relevant model for studying esophageal squamous epithelial growth and differentiation. However, the full potential of this culture system to model human disease conditions such as BE has not been fully explored. Fibroblasts are an essential component of the 3D OTC system; they remodel the matrix and secrete factors that support squamous epithelial cell proliferation and differentiation [20]. BE epithelial cells probably require different factors to sustain their growth. Several studies have identified some of these factors; in vivo they include bone morphogenetic protein 4 and wingless int- 1 protein-2 [21,22], and in vitro they include Noggin, wingless int-1 protein-3a, and R-spondin-1 [23]. In addition, the activity of the oncogene cyclooxygenase- 2 is induced in fibroblasts as well as in the epithelium in GERD and BE [24]. Our laboratory previously demonstrated that endogenous overexpression of cyclooxygenase- 2 in epithelial cells in 3D OTC results in the development of intestinal mucin-filled epithelial cysts, consistent with the progression of BE development [25]. Nevertheless, the extent that factors produced from fibroblasts influence $\mathrm{BE}$ disease development and/or progression is largely unknown.

In 2011, four groups independently published descriptions of methods by which human intestinal and colonic stem cells can be maintained and expanded in culture to mimic in vivo microenvironments [23,26-28] (Figure 2a). These techniques built upon and extended a slightly older, more established method of culturing mouse small intestine stem cells [29]. In this culture method, human intestinal and colonic crypts or purified stem cells are embedded in Matrigel. Over several days these cells form spherical or elongated oval structures with a crypt-like lumen, referred to as human enterospheres [30] (Figure 2b). Small intestine and colon spheres can expand into multilobulated enteroids (Figure 2c) and colonoids that mimic the ordered structure of the epithelium complete with crypts containing multipotent columnar base stem cells and Paneth cells. The remaining cell types, including enterocytes, goblet cells, and enteroendocrine cells $[23,30]$, can be observed in larger cysts away from the stem cell compartment (Figure 2a). While the majority of studies conducted with human enteroids and 


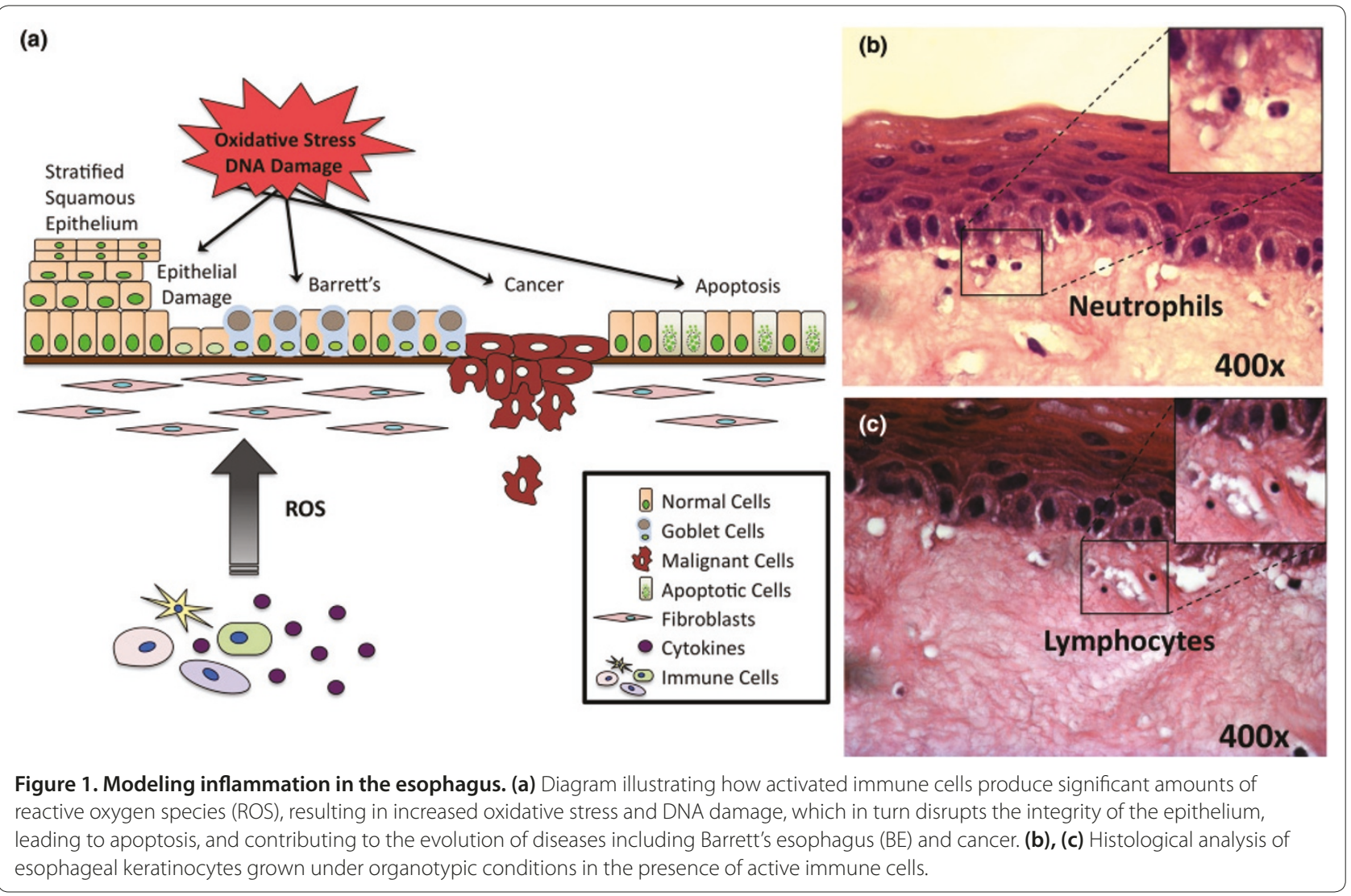

colonoids thus far have focused on stem cell characterization and regenerative medicine, there is immense potential for this culture system in GI research, particularly to model GVHD and IBD. However, they have not as yet been widely adopted to model these and other human disease conditions.

\section{Future needs and research directions}

Our work seeks to develop novel multicellular in vitro human tissue engineered models that physiologically recapitulate the acute and chronic inflammatory microenvironment in order to model the effects of oxidative injury on the epithelial cells of the esophagus and intestine. These studies are anticipated to yield well-characterized culture systems that are representative of the pathogenesis of GERD, BE, GVHD, and IBD, thereby providing useful laboratory models for these conditions. Experimental models for these conditions utilizing human tissues and cells are an unmet research imperative.

In addition, we anticipate more specific products of our efforts. The development of a dynamic multicellular system to physiologically model inflammation will permit a more mechanistic understanding of the contributions of infiltrating immune cells and oxidative stress to DNA damage and epigenetic changes, particularly regarding their contribution to the progression to dysplasia and cancer. Moreover, these novel human cell tissue models can place human mucosal immunology research back in its appropriate context; that is, human epithelial systems. Pursuit of this end will require modifications of our currently established 3D organotypic and intestinal enteroid/colonoid culture systems to reflect the inflammatory processes active during human diseases such as GERD, BE, GVHD, and IBD. Lastly, these human cell-based models of chronic inflammatory conditions can serve as a platform for testing novel therapeutic drugs and chemopreventive agents.

We are presently pursuing several important research directions. The first is to better characterize the contributions of fibroblasts to the growth and differentiation of the squamous epithelium in the OTC system. Specifically, we are exploring whether fibroblasts function primarily to remodel the underlying matrix by altering physical properties such as stiffness, or instead secrete required growth and maintenance factors, or some combination of both. Moreover, we are investigating whether we can engineer the fibroblasts to secrete other growth factors that support columnar epithelial growth, to determine whether this can promote epithelial metaplasia as observed in BE. 


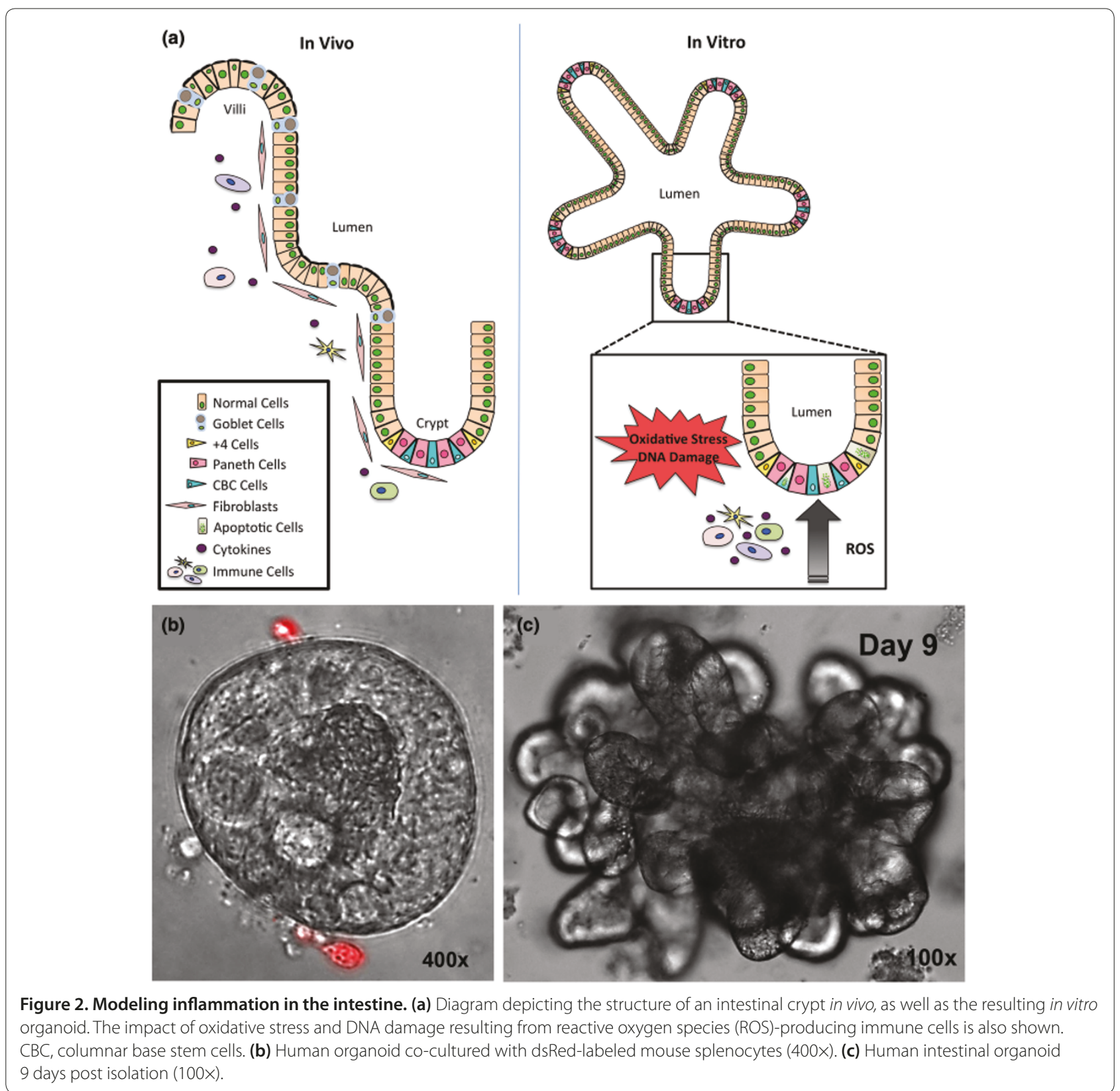

We are actively exploring modifications to both the esophageal OTC and intestinal enteroid/organoid culture systems that will permit the inclusion of viable purified human immune cells (Figures $1 \mathrm{~b}, \mathrm{c}$ and $2 \mathrm{~b}$ ). We plan to further refine the human OTC and intestinal enteroid/ colonoid cultures to include additional microenvironmental cell types and factors to better and more physiologically model human disease. For instance, eliciting a polarized response of purified human immune cells against the mismatched human leukocyte antigen of the growing human enteroid would provide an excellent model for GVHD. Once optimized, these co-culture systems could evaluate the efficacies of novel immunosuppressant drugs and strategies to treat GVHD.

\section{Conclusion}

Our research efforts are focused on developing physiologically relevant human cell-based tissue culture models for chronic inflammatory conditions of the GI tract. With these systems we will mechanistically explore the effect of the inflammatory response on epithelial oxidative stress and DNA damage. Ultimately, these novel model systems have the potential to permit the rapid testing of hypotheses and advance our understanding of chronic 
inflammatory disorders. Moreover, this research will foster the development of novel therapeutic and preventive strategies that will improve the lives and wellbeing of patients afflicted with these important clinical conditions.

\section{Abbreviations}

BE, Barrett's esophagus; 3D, three-dimensional; GERD, gastroesophageal reflux disease; Gl, gastrointestinal; GVHD, graft-versus-host disease; IBD, inflammatory bowel disease; IFN, interferon; IL, interleukin; OTC, organotypic culture; ROS, reactive oxygen species.

\section{Competing interests}

The authors declare that they have no competing interests.

\section{Authors' contributions}

KGH was responsible for drafting the manuscript and diagram design. JDB was responsible for drafting the manuscript and for image acquisition. GWF, JY, MGM, and AKR were responsible for the concept and critical manuscript revision. JPL was responsible for the concept and experimental design, critical manuscript revision and final approval. All authors read and approved the final manuscript.

\section{Acknowledgements}

The authors would like to thank the University of Pennsylvania Morphology and Pathology Imaging Core facility for their technical expertise and assistance. Tissue samples were kindly provided by the Cooperative Human Tissue Network, which is funded by the National Cancer Institute. This work is supported as part of the Integrated Microphysiological Systems program and the Intestinal Stem Cell Consortium with funding to JPL (TR 000536 and DK 085551) and to MGM (DK 085535). This work was also supported by an NCl Program Project P01 CA098101 (to AKR) and by the Morphology, Cell Culture, and Molecular Biology Core Facilities of the Center for Molecular Studies in Digestive and Liver Disease at the University of Pennsylvania (P30-DK050306 and P01 (A098101 to AKR). Publication costs were paid by the Integrated Microphysiological Systems program with funding to JPL (TR 000536).

\section{Declarations}

Publication of this supplement has not been supported by sponsorship. Articles have undergone the journal's standard review process. The Editors declare that they have no competing interests.

This article has been published as part of Stem Cell Research \& Therapy Volume 4 Supplement 1, 2013: Stem cells on bioengineered microphysiological platforms for disease modeling and drug testing. The full contents of the supplement are available online at http://www.stemcellres.com/supplements/4/S1.

\section{Author details}

'Division of Gastroenterology, Department of Medicine, Abramson Cancer Center, University of Pennsylvania, 3451 Walnut Street, Philadelphia, PA 19104, USA. ${ }^{2}$ Department of Pathology, University of Pittsburgh Cancer Institute, University of Pittsburgh School of Medicine, 5117 Centre Avenue, Hillman Cancer Center Research Pavilion, Pittsburgh, PA 15213, USA. ${ }^{3}$ Department of Radiation Oncology, University of Pittsburgh Cancer Institute, University of Pittsburgh School of Medicine, 5117 Centre Avenue, Hillman Cancer Center Research Pavilion, Pittsburgh, PA 15213, USA. “Department of Pediatrics, Division of Gastroenterology and Nutrition, Mattel Children's Hospital and the David Geffen School of Medicine, University of California at Los Angeles, 10833 Le Conte Avenue, Los Angeles, CA 90095-1752, USA.

Published: 20 December 2013

\section{References}

1. Kim YJ, Kim EH, Hahm KB: Oxidative stress in inflammation-based gastrointestinal tract diseases: challenges and opportunities. J Gastroenterol Hepatol 2012, 27:1004-1010.

2. Federico A, Morgillo F, Tuccillo C, Ciardiello F, Loguercio C: Chronic inflammation and oxidative stress in human carcinogenesis. Int $J$ Cancer 2007, 121:2381-2386.
3. Feagins LA, Zhang HY, Zhang X, Hormi-Carver K, Thomas T, Terada LS, Spechler SJ, Souza RF: Mechanisms of oxidant production in esophageal squamous cell and Barrett's cell lines. Am J Physiol Gastrointest Liver Physiol 2008, 294:G411-G417.

4. Kong J, Stairs DB, Lynch JP: Modeling Barrett's oesophagus. Biochem Soc Trans 2011, 38:321-326.

5. Spechler SJ, Fitzgerald RC, Prasad GA, Wang KK: History, molecular mechanisms, and endoscopic treatment of Barrett's esophagus. Gastroenterology 2010, 138:854-869.

6. Sharma P: Clinical practice. Barrett's esophagus. N Engl J Med 2009, 361:2548-2556.

7. Espana EM, Shah S, Santhiago MR, Singh AD: Graft versus host disease: clinical evaluation, diagnosis and management. Graefes Arch Clin Exp Ophthalmol 2013, 251:1257-1266.

8. Scharl M, Rogler G: Inflammatory bowel disease: dysfunction of autophagy? Dig Dis 2012, 30(Suppl 3):12-19.

9. Yuen E, Romney M, Toner RW, Cobb NM, Katz PO, Spodik M, Goldfarb NI: Prevalence, knowledge and care patterns for gastro-oesophageal reflux disease in United States minority populations. Aliment Pharmacol Ther 2010, 32:645-654.

10. Quante M, Abrams JA, Lee Y, Wang TC: Barrett esophagus: what a mouse model can teach us about human disease. Cell Cycle 2012, 11:4328-4338.

11. Washington K, Jagasia M: Pathology of graft-versus-host disease in the gastrointestinal tract. Hum Pathol 2009, 40:909-917.

12. Loftus Jr EV: Epidemiology and risk factors for colorectal dysplasia and cancer in ulcerative colitis. Gastroenterol Clin North Am 2006, 35:517-531.

13. Fein M, Peters $J H$, Chandrasoma P, Ireland AP, Oberg S, Ritter MP, Bremner CG, Hagen JA, DeMeester TR: Duodenoesophageal reflux induces esophageal adenocarcinoma without exogenous carcinogen. J Gastrointest Surg 1998, 2:260-268

14. Garman KS, Orlando RC, Chen X: Review: Experimental models for Barrett's esophagus and esophageal adenocarcinoma. Am J Physiol Gastrointest Liver Physiol 2012, 302:G1231-G1243.

15. Fitzgerald RC, Onwuegbusi BA, Bajaj-Elliott M, Saeed IT, Burnham WR, Farthing MJ: Diversity in the oesophageal phenotypic response to gastrooesophageal reflux: immunological determinants. Gut 2002, 50:451-459.

16. Saleh M, Elson CO: Experimental inflammatory bowel disease: insights into the host-microbiota dialog. Immunity 2011, 34:293-302.

17. O'Hagan HM, Wang W, Sen S, Destefano Shields C, Lee SS, Zhang YW, Clements EG, Cai Y, Van Neste L, Easwaran H, Casero RA, Sears CL, Baylin SB: Oxidative damage targets complexes containing DNA methyltransferases, SIRT1, and polycomb members to promoter CpG islands. Cancer Cell 2011, 20:606-619.

18. Suzuki N, Yasui M, Geacintov NE, Shafirovich V, Shibutani S: Miscoding events during DNA synthesis past the nitration-damaged base 8-nitroguanine. Biochemistry 2005, 44:9238-9245.

19. Agarwal A, Polineni R, Hussein Z, Vigoda I, Bhagat TD, Bhattacharyya S, Maitra A, Verma A: Role of epigenetic alterations in the pathogenesis of Barrett's esophagus and esophageal adenocarcinoma. Int J Clin Exp Pathol 2012, 5:382-396

20. Kalabis J, Wong GS, Vega ME, Natsuizaka M, Robertson ES, Herlyn M Nakagawa H, Rustgi AK: Isolation and characterization of mouse and human esophageal epithelial cells in 3D organotypic culture. Nat Protoc 2012, 7:235-246

21. Wang DH, Clemons NJ, Miyashita T, Dupuy AJ, Zhang W, Szczepny A, Corcoran-Schwartz IM, Wilburn DL, Montgomery EA, Wang JS, Jenkins NA, Copeland NA, Harmon JW, Phillips WA, Watkins DN: Aberrant epithelialmesenchymal hedgehog signaling characterizes Barrett's metaplasia. Gastroenterology 2010, 138:1810-1822.

22. Clement G, Braunschweig R, Pasquier N, Bosman FT, Benhattar J: Alterations of the wnt signaling pathway during the neoplastic progression of Barrett's esophagus. Oncogene 2006, 25:3084-3092.

23. Sato T, Stange DE, Ferrante M, Vries RG, Van Es JH, Van den Brink S, Van Houdt WJ, Pronk A, Van Gorp J, Siersema PD, Clevers H: Long-term expansion of epithelial organoids from human colon, adenoma, adenocarcinoma, and Barrett's epithelium. Gastroenterology 2011, 141:1762-1772.

24. Buttar NS, Wang KK, Anderson MA, Dierkhising RA, Pacifico RJ, Krishnadath KK, Lutzke LS: The effect of selective cyclooxygenase- 2 inhibition in Barrett's esophagus epithelium: an in vitro study. J Natl Cancer Inst 2002, 94:422-429.

25. Kong J, Crissey MA, Stairs DB, Sepulveda AR, Lynch JP: Cox2 and 
$\beta$-catenin/T-cell factor signaling intestinalize human esophageal keratinocytes when cultured under organotypic conditions. Neoplasia 2011, 13:792-805.

26. Jung P, Sato T, Merlos-Suarez A, Barriga FM, Iglesias M, Rossell D, Auer H, Gallardo M, Blasco MA, Sancho E, Clevers H, Batlle E: Isolation and in vitro expansion of human colonic stem cells. Nat Med 2011, 17:1225-1227.

27. Lahar N, Lei NY, Wang J, Jabaji Z, Tung SC, Joshi V, Lewis M, Stelzner M, Martin MG, Dunn JC: Intestinal subepithelial myofibroblasts support in vitro and in vivo growth of human small intestinal epithelium. PLoS One 2011, 6:e26898.

28. Spence JR, Mayhew CN, Rankin SA, Kuhar MF, Vallance JE, Tolle K, Hoskins EE, Kalinichenko VV, Wells SI, Zorn AM, Shroyer NF, Wells JM: Directed differentiation of human pluripotent stem cells into intestinal tissue in vitro. Nature 2011, 470:105-109.
29. Sato T, Vries RG, Snippert HJ, van de Wetering M, Barker N, Stange DE, van Es $J H$, Abo A, Kujala P, Peters PJ, Clevers H: Single Lgr5 stem cells build cryptvillus structures in vitro without a mesenchymal niche. Nature 2009, 459:262-265.

30. Stelzner M, Helmrath M, Dunn JC, Henning SJ, Houchen CW, Kuo C, Lynch J, Li L, Magness ST, Martin MG, Wong MH, Yu J: NIH Intestinal Stem Cell Consortium. A nomenclature for intestinal in vitro cultures. Am J Physiol Gastrointest Liver Physiol 2012, 302:G1359-G1363.

\section{doi:10.1186/scrt366}

Cite this article as: Hartman KG, et al:: Modeling inflammation and oxidative stress in gastrointestinal disease development using novel organotypic culture systems. Stem Cell Research \& Therapy 2013, 4(Suppl 1):S5. 